\title{
Equipamentos públicos de lazer e esporte: o cenário institucional de municípios que implementaram o Programa Esporte e Lazer da Cidade
}

\author{
Public leisure and sport equipment: the institutional scenario of municipalities that \\ implemented the Programa Esporte e Lazer da Cidade \\ Instalaciones públicas de ocio y deporte: el conjunto institucional de los municipios que \\ implementaron el Programa Esporte e Lazer da Cidade
}

Bruno Ocelli Ungheria,* (D), Hélder Ferreira Isayamab ${ }^{\mathrm{a}}$ (D)

Palavras-chave

Lazer;

Esporte;

Política pública;

Equipamentos.

\begin{abstract}
RESUMO
O estudo buscou analisar os equipamentos públicos de lazer e esporte dos municípios que implementaram o PELC entre 2013 e 2017. Para isso, aplicou-se um questionário digital aos 105 municípios elegíveis, analisando os dados por estatística descritiva. Identificou-se a prevalência de instalações destinadas aos esportes coletivos e às ginásticas - o que também se materializou na concepção de novos equipamentos. Verificou-se a necessidade de se qualificar serviços auxiliares como estacionamento para automóveis e bicicletas, postos de hidratação, banheiros / vestiários públicos. Conclui-se que a passagem do PELC pelas cidades pode induzir reflexões sobre relações indissociáveis entre os equipamentos públicos e a garantia de direitos sociais.
\end{abstract}

\section{ABSTRACT}

The study aimed to analyze the public leisure and sports equipment of the municipalities that implemented the PELC between 2013 and 2017. For this, a digital questionnaire was applied to the 105 eligible municipalities, analyzing the data by descriptive statistics. The prevalence of equipments for collective sports and gymnastics was identified - which also materialized in the design of new areas. It was verified the need to qualify ancillary services such as parking for cars and bicycles, hydration stations, toilets / public changing rooms. It is concluded that the passage of PELC through cities can induce reflections on inseparable relations between public equipment and the guarantee of social rights.

Palabras clave

Ocio;

Deporte;

Política pública; Instalaciones.

\section{RESUMEN}

El estudio tuvo como objetivo analizar el ocio público y el equipamiento deportivo de los municipios que implementaron el PELC entre 2013 y 2017. Para ello, se aplicó un cuestionario digital a los 105 municipios elegibles, analizando los datos mediante estadísticas descriptivas. Se identificó la prevalencia de instalaciones para deportes colectivos y gimnasia, que también se materializó en el diseño de nuevas estructuras. Se verificó la necesidad de calificar servicios auxiliares tales como aparcamiento para coches y bicicletas, estaciones de hidratación, baños / vestuarios públicos. Se concluye que el paso de PELC por las ciudades puede inducir reflexiones sobre las relaciones inseparables entre el equipamiento público y la garantía de los derechos sociales. 


\section{INTRODUÇÃO}

Abordar o esporte e o lazer como campo, significa reconhecer seus respectivos papéis na vida social, legitimando a busca pelo desenvolvimento de pesquisas voltadas à compreensão de seus sentidos e significados, nas variadas formas de participação, experimentação e fruição cultural. Para Isayama et al. (2014), as relações entre esporte e lazer são presentes desde a conformação do campo esportivo no país e tem se fortalecido ao longo do tempo. Isso pode ser visualizado, inclusive, por meio do privilégio dado às atividades físicas nos programas pioneiros de lazer, da formação dos primeiros profissionais do campo e da influência norte-americana que sempre apresentou um forte relacionamento entre os dois campos. Melo (2008) anuncia a necessidade de compreender o lazer e o esporte de forma aprofundada, compreendendo-os como práticas articuladas a um conjunto de valores, normas, hábitos e formas de viver que são dinâmicas, relacionando-se às dimensões da vida como a social, o trabalho, a educação, a política, a arte, a espiritualidade e a linguagem.

Segundo Melo e Fortes (2010), o estudo sobre o esporte e o lazer contribui para o entendimento da sociedade como um todo. Enfatizam que tais dimensões fazem parte do patrimônio de um povo, da memória afetiva de indivíduos e grupos, perpassando a formulação de identidades de classe, gênero, etnia, entre outras - estabelecendo a cultura como ponto de partida para a análise em questão. Nessa esteira, o lazer e o esporte podem refletir a relação das estruturas econômica, política e ideológica de uma sociedade, constituindo-se como objeto de estudo articulado com o contexto social (Starepravo, 2006). Por esse motivo, se fazem presentes na vida política, principalmente por se fazerem reconhecer como direitos sociais garantidos constitucionalmente - demonstrando sua alavancagem na agenda política.

Entrementes, a visibilidade alcançada pelo esporte e pelo lazer no jogo político, não os garante como foco da intervenção do Estado, mas possibilita a criação de espaços para reflexão e discussão acerca de suas potencialidades relacionadas ao desenvolvimento social. Para que isso ocorra, é preciso considerar a oferta de condições mínimas ao acesso das pessoas, que podem ser verificadas por diferentes aspectos, dentre eles os espaciais e estruturais. Como destacam Ungheri e Isayama (2019), a oferta de espaços e equipamentos públicos para as vivências de lazer e esporte é uma das formas de se promover o acesso dos cidadãos a essas práticas e, por esse motivo, apresenta-se como possibilidade de intervenção do poder público. Nessa perspectiva, debruçar sobre as políticas de esporte e lazer e suas relações com o ambiente urbano requer o desenvolvimento de uma abordagem multicausal. Questões como mobilidade urbana, segurança pública, iluminação, limpeza, horários de funcionamento, atividades desenvolvidas e recursos materiais podem ser tidos como barreiras ou catalisadores do processo de apropriação de uma comunidade aos bens e serviços ofertados em seus territórios (Ungheri e Isayama, 2019).

Fica evidente, então, a necessidade de se conceber espaços e equipamentos públicos que sejam pensados democraticamente, pela lógica de ampliação da aderência social. Nesse sentido, vale a pena pensar na transição entre espaço e lugar, em que o elemento central está no sentimento de pertencimento por parte das pessoas. Para Gehl (2013), um dos pilares para concepção e consolidação de boas cidades é promover o maior número possível de encontros entre as pessoas. Trata-se, portanto, de um ambiente urbano convidativo às relações sociais comunitárias, em que os sujeitos desfrutem de espaços e equipamentos confortáveis. Nesse aspecto, é imperativo chamar atenção para a vocação convidativa da cidade, que induz comportamentos capazes de traduzir as dimensões culturais das diferentes comunidades.

Rechia (2003) chama atenção para a possibilidade de vincular equipamentos públicos a características de diferentes etnias e a projetos culturais capazes de criarem identidade e de conferirem vitalidade aos lugares. Nesse contexto, não se pode negar a interferência exercida pela reprodução do capital em relação à configuração das cidades, mas é indispensável a busca pela construção de uma agenda pública, que também considere o protagonismo da cultura na construção de ações e significados vinculados à paisagem urbana das cidades.

Sob esse prisma, o objetivo do estudo foi diagnosticar o cenário institucional dos municípios que implementaram o Programa Esporte e Lazer da Cidade (PELC) entre os anos 2013 e 2017, tendo como foco os equipamentos públicos de lazer e esporte disponíveis à população (Brasil, 2017). Almejou-se, com isso, lançar luz às tipologias estruturais privilegiadas pelos municípios e, a reboque, aos interesses culturais potencializados pela ocorrência dos equipamentos. Com isso, espera-se municiar reflexões sobre os resultados percebidos por políticas públicas orientadas pela municipalização, além de elementos ligados à natureza dos investimentos públicos no campo do lazer e do esporte, haja visto que o gerenciamento das informações que emergem de suas ações pode nortear futuras tomadas de decisão no âmbito do planejamento e da administração pública.

\section{PERCURSO METODOLÓGICO}

A pesquisa em tela se contextualiza pelas experiências do Programa Esporte e Lazer da Cidade (PELC), lançando luz às particularidades da infraestrutura municipal de lazer e esporte, sob a perspectiva de sua diretriz de municipalização. Criado em 2003, o PELC concretiza um investimento público nas políticas de esporte e lazer, objetivando alterar seu patamar de política governamental para a dimensão de política de Estado. O Programa, além de proporcionar a prática de atividades físicas, culturais e de lazer que envolvem todas as faixas etárias, incluindo pessoas com deficiência, 
estimula a convivência social, a formação de gestores e lideranças comunitárias, fomenta a pesquisa e a socialização do conhecimento.

Por se tratar de uma pesquisa de cunho avaliativo, é preciso ter bem definidas suas finalidades, para não ser compreendida como processo de controle ou legitimador das decisões já tomadas em relação ao PELC. Reconhece-se, assim, a avaliação como instrumento de gestão que propicia identificar diferenças entre o resultado e o planejado, por meio de indicadores que orientam sua análise. Cotta (1998) aponta que a principal característica da avaliação é seu caráter aplicado, enfatizando que o nível federativo (nacional, estadual ou municipal) das intervenções públicas possui particularidades e influencia a escolha da metodologia de avaliação mais adequada.

Esclarece-se que o estudo em questão se configura como recorte de uma pesquisa com maior abrangência, cuja etapa inicial foi dedicada à análise dos Projetos Técnicos Pedagógicos de todos os 276 municípios que tiveram seus convênios aprovados pelo extinto Ministério do Esporte (ME), desde a implementação da diretriz de municipalização determinada no final de 2012. Todavia, após acesso autorizado pelo ME ao "Mimboé" - Sistema de Monitoramento e Avaliação do Ministério do Esporte, verificou-se que foram executados, de fato, somente 105 convênios.

Sob esse prisma, foi aplicado um questionário digital junto aos municípios que implementaram o Programa, traçando-se como marco temporal os convênios com encerramento previsto para, no máximo, dezembro de 2017. O ponto de partida para inclusão foi janeiro de 2013, quando os projetos em execução passaram a incluir a municipalização como referência. $O$ instrumento original para coleta dos dados continha 40 questões, sendo 38 fechadas e 2 abertas, elaboradas sob os seguintes tópicos de análise: (i) envolvimento com o PELC (ii) mecanismos de participação (iii) financiamento e legislação sobre esporte e lazer (iv) quadro de profissionais (v) formação continuada do quadro de profissionais (vi) infraestrutura de esporte e lazer. Para fins do presente artigo, mobilizou-se somente as informações elencadas à partir deste último tópico.

A partir do consentimento do Comitê de Ética em Pesquisa (CAAE 60385316.0000.5149), aplicou-se o questionário digital, precedido de uma Carta de Abertura, legitimada por um Termo de Consentimento Livre e Esclarecido. Em relação aos respondentes, foi definido que os dados seriam coletados de forma oficial, encaminhando-se o instrumento aos órgãos responsáveis pela gestão do convênio nos municípios analisados, orientando sua resposta por um técnico de carreira ou um agente formado pelo Programa. Para elaboração e aplicação do questionário, bem como para armazenamento e tratamento das informações, foi utilizado o software online "Survio".
A coleta de dados se iniciou em julho de 2018 e, após 6 meses, dos 105 municípios elegíveis, 19 responderam ao questionário. As informações emergentes foram analisadas por intermédio de estatística descritiva, culminando em três categorias de análise estabelecidas à posteriori. Duas delas, estabelecidas por variáveis nominais (May, 2004), são dedicadas à demonstração dos tipos de equipamentos públicos de lazer e esporte presentes nos municípios, distinguindo-se aqueles concebidos após a realização dos convênios junto ao PELC. Uma terceira categoria, com variáveis ordinárias (May, 2004), orienta-se pela classificação das respostas obtidas em relação às condições de acesso e permanência nas instalações públicas em tela.

\section{RESULTADOS E DISCUSSÃO}

Tendo como pano de fundo a passagem do PELC pelos municípios analisados, apresenta-se um panorama dos aspectos infra estruturais que possam ter sofrido alguma influência dos princípios de municipalização do Programa. Trata-se de uma tentativa de identificar alterações na dinâmica das cidades, induzidas pelos anos de convênio junto ao extinto Ministério do Esporte. Para isso, foram definidos quatro eixos de análise que pudessem clarificar o entendimento sobre os possíveis indicadores de municipalização do Programa, a saber: (i) eixo legal; (ii) eixo administrativo; (iii) eixo gerencial; (iv) eixo estrutural. Este último eixo se configura como objeto em foco no presente artigo, sendo relevante reconhecer que o sucesso ou o fracasso das intervenções governamentais é multifatorial, mas para compreensão do espectro analisado, a estratificação dos dados pode ser favorável ao entendimento do todo.

Com amparo em Ungheri e Isayama (2020), reconhece-se que estabelecer relações entre indicadores próprios de lazer e esporte junto aos marcadores do desenvolvimento social e econômico, amplia o potencial de compreensão dos resultados obtidos pelas políticas públicas. Nessa esteira, registra-se que as municipalidades apreciadas possuem diferenças significativas quanto à densidade populacional, o que interfere na complexidade das articulações governamentais necessárias ao desenvolvimento das políticas públicas. Somado a isso, também foram encontradas diferenças no PIB per capta e no Índice de Gini, demonstrando assimetrias no que tange à distribuição de riquezas entre os municípios em análise. É possível inferir que as dissonâncias identificadas interfiram na capacidade de investimento e gestão das cidades, o que pode ser verificado por estudos futuros que se dediquem especificamente a este objeto. Entretanto, cabe ressaltar que, como demonstram Soares e Guadanini (2018), os indicadores dos municípios envolvidos com o PELC se mostram superiores às médias encontradas nos demais municípios brasileiros.

Não se pode perder de vista o exame crítico sobre as formas com que as administrações públicas se valem dos diferentes tipos de recursos destinados 
ao esporte e ao lazer. Tratando especificamente do PELC, Figuerôa et al. (2014) concluíram que, desde 2009, 90\% dos recursos destinados ao Programa foram aplicados em infraestrutura, o que não garante a oferta de práticas participativas aos cidadãos brasileiros. Sobre isso, Castro (2016) investigou as dotações orçamentárias para o PELC entre 2004 e 2011, concluindo que o Programa não configurou como prioritário para a pasta que o administrara. Apesar de somar o maior volume de recursos financeiros para a função descrita como "desporto e lazer", os cortes orçamentários no período analisado e os créditos suplementares aos programas de rendimento, criaram um distanciamento significativo entre as políticas de fomento às diferentes manifestações do esporte e do lazer. Além disso, tendo em vista a liquidação dos recursos destinados ao esporte e ao lazer, o PELC apresentou declínios paulatinos nos planos plurianuais, saindo de $68,9 \%$ entre $2004-2007$, culminando em $57,8 \%$ entre $2008-2011$, o segundo menor entre os chamados programas finalísticos.

Os dados apresentados por Castro (2016) corroboram com os apontamentos de Figuerôa et al. (2014), uma vez que, mesmo quando recebeu recursos extraordinários, ou complementares, o PELC destinou-os à infraestrutura. Em 2007, por exemplo, o Programa foi contemplado com $\mathrm{R} \$ 97,9$ milhões, quase totalmente direcionados à implementação de infraestrutura esportiva em áreas de vulnerabilidade social. Ao confrontar a utilização dos incrementos orçamentários com as ações afetadas por cancelamentos e cortes, Castro (2016) aponta que esses últimos impactaram prioritariamente a promoção de eventos de lazer, o fomento de pesquisas e execução de eventos científicos na área. Diante disso, a tomada de decisão em relação aos cortes orçamentários geralmente afeta as ações que impactam diretamente os possíveis beneficiários, desconsiderando a possibilidade de, por exemplo, reavaliação acerca da pertinência dos investimentos ligados à infraestrutura. Isto posto, a Tabela 1 elenca os equipamentos que compõem o cenário atual dos municípios.

Diante dos dados apresentados, nota-se a hegemonia de alguns tipos de equipamentos como quadras poliesportivas, campos de futebol, ginásios e academias a céu aberto. Sobre essas últimas, como aponta Abade (2016), existe uma perspectiva nacional em universalizar e democratizar seu acesso por parte da população, tendo em vista o baixo custo e a baixa complexidade de implantação. A autora destaca que, em geral, não existem iniciativas voltadas para a manutenção desses espaços, o que indica falhas na gestão pública, que busca solucionar ou realizar intervenções de forma imediatista, tornando-as relativamente perecíveis. Cenário semelhante foi descrito por Lopes e Isayama (2011) que, em relação aos equipamentos públicos de esporte e lazer, observaram uma predominância de ações pautadas na concepção de novas estruturas, sem o planejamento acerca de sua animação e manutenção. Com isso, há uma possibilidade de que os espaços públicos se tornem obsoletos com o passar do tempo, pela indisponibilidade dos recursos necessários para sua gestão.

No caso do PELC, Figuerôa et al. (2014) e Castro (2016) demonstram que aproximadamente $90 \%$ dos recursos foram utilizados para custeio de infraestrutura. Cumpre esclarecer que uma das principais fontes de recurso para os convênios se origina de emendas parlamentares que, conforme Ungheri e Isayama (2019), geralmente são destinadas à implementação de equipamentos esportivos - não ao funcionamento de núcleos e ações permanentes. Cabe mencionar que as emendas parlamentares promovem diferentes entendimentos sobre sua pertinência junto ao sistema político brasileiro. Sodré e Alves (2010) destacam a existência de duas correntes de pensamento sobre o assunto, sendo que uma delas defende sua existência, por garantir legitimidade ao sistema de representatividade política. Outra corrente as defende pela necessidade de descentralização de recursos, uma vez que os responsáveis pelo bem-estar e pela qualidade de vida da população são, em grande parte, os municípios. Por outro lado, são inúmeros os argumentos que defendem a extinção das emendas parlamentares, justificada pela dificuldade de fiscalização e pela quantidade de escândalos sobre malversação dos recursos advindos de emendas nas últimas décadas - especialmente por envolver moedas de troca entre os poderes executivos e legislativos.

Em adição, apesar de serem mecanismos com potencial de financiamento das práticas de esporte e lazer, as emendas parlamentares estão sujeitas ao capital político possível de ser obtido pelo ator legislativo.

Tabela 1. Equipamentos específicos de esporte e lazer presentes nos municípios analisados.

\begin{tabular}{lcc}
\hline \multicolumn{1}{c}{ Tipo de Equipamento } & N & $\begin{array}{c}\text { Presença nos } \\
\text { municípios }\end{array}$ \\
\hline Praça & 19 & $100 \%$ \\
Quadra Poliesportiva & 18 & $94,7 \%$ \\
Campo de Futebol & 17 & $89,5 \%$ \\
Academia ao Ar Livre & 16 & $84,2 \%$ \\
Ginásio & 16 & $84,2 \%$ \\
Piscina & 10 & $52,6 \%$ \\
Pista de Corrida & 10 & $52,6 \%$ \\
Teatro & 10 & $52,6 \%$ \\
Área para Esportes Radicais & 9 & $47,4 \%$ \\
Parque & 8 & $42,1 \%$ \\
Cinema & 7 & $36,8 \%$ \\
Quadra de Tênis & 7 & $36,8 \%$ \\
Shopping & 6 & $31,6 \%$ \\
Outros & 1 & $5,3 \%$ \\
Não existem equipamentos de & 0 & $0 \%$ \\
esporte e lazer na cidade & & \\
\hline
\end{tabular}

Fonte: elaborada pelos autores. 
Entende-se que este é um entrave significativo para os gestores que as prospectam, uma vez que além de concorrerem com outras áreas de intervenção do Estado, também podem esbarrar numa perspectiva cultural política que valoriza o esporte de rendimento, a construção de equipamentos desvinculada dos interesses e necessidades da população e a execução de eventos, sobretudo aqueles de grande porte e os megaeventos. Marchi e Almeida (2010), Figuerôa et al. (2014) e Castro (2016) demonstraram que o maior montante de investimentos nas ações de esporte e lazer foi destinado às manifestações do esporte de rendimento e aos programas diretamente vinculados à Copa do Mundo de Futebol FIFA 2014 e aos Jogos Olímpicos Rio 2016. Uma possível explicação para esse cenário, proposta por Marchi e Almeida (2010), está na histórica relação entre esporte e política, sobretudo no potencial gerador de capital e poder político a partir de conquistas esportivas de alcance mundial.

O panorama apresentado demonstra a importância da gestão profissional dos equipamentos de esporte e lazer, pois, como afirmam Bramante e Pina (2018), não basta disponibilizar os espaços às pessoas para equacionar e resolver os problemas identificados em um determinado território. Os autores defendem a adoção de uma gestão estratégica para o campo, pautada na relação entre demanda e oferta, em que o papel do gestor público seja o de criar meios para educar pelo e para o esporte e o lazer, através do alargamento do repertório de opções de experiências lúdicas. Tais experiências, no entendimento de Silva e Pinto (2017), partem de uma perspectiva cidadã, em que os sujeitos se educam para a autonomia, por meio de experiências culturais mobilizadoras de reflexões sobre o contexto social. Ao considerar a proposta de uma gestão pautada na demanda e na oferta, percebe-se que o processo educativo, com fundamento no exercício efetivo e lúdico da cidadania, promove uma formação emancipadora dos sujeitos que, em alguma medida, passam a ampliar seus horizontes culturais, qualificando assim suas demandas em relação ao poder público.

$\mathrm{Na}$ esteira dos aspectos gerenciais, a infraestrutura de esporte e lazer é um tema frequentemente presente nas políticas públicas, assumindo, em boa medida, o protagonismo acerca da intervenção dos agentes públicos. Isso porque, a percepção social sobre o atendimento de seus direitos passa diretamente pelo impacto causado por uma transformação física na cidade, tangível, visível às pessoas, potencializando a apreensão de capital político por parte dos governantes. Apesar deste não poder ser considerado o único viés da intervenção pública, Bramante e Pina (2018) afirmam que uma política municipal de esporte e lazer está diretamente associada ao arranjo e organização dos espaços urbanos. Para os autores, a capacidade de cada ambiente para receber as pessoas, será sempre função da relação entre espaço físico e seus sistemas de infraestrutura e estruturas de apoio. Nesse sentido, é imperativo diversificar os espaços e equipamentos disponíveis à população, o que pode ser alcançado pela concepção de espaços modulares e polivalentes, permitindo o uso múltiplo e a fácil conversão, conforme as atividades demandadas por seus frequentadores (Bramante e Pina, 2018).

No entendimento de Gehl (2013), é comum observar a ausência de um trabalho cuidadoso, em muitas cidades pelo mundo, voltado à oferta de espaços que oportunizem a permanência dos usuários, "não há motivo para se permanecer ali" (p. 137). Este é um elemento central nas discussões sobre os espaços e equipamentos públicos, uma vez que a ausência de um conforto mínimo gera o afastamento dos sujeitos, que por sua vez reduzem suas relações afetivas com a cidade. Para Rechia (2003), esse fator pode tornar os cidadãos descomprometidos com o espaço físico em que vivem, reduzindo sua vitalidade. É preciso analisar como os habitantes dos centros urbanos pensam sobre os espaços disponíveis para si, ou seja, como aspiram por novas maneiras de viver o cotidiano. Nessa abordagem, torna-se necessário pensar sobre os equipamentos que foram construídos após a implementação do PELC, na intenção de verificar possíveis parcelas de contribuição do Programa junto ao desenho dos municípios.

A concepção de novos equipamentos públicos não depende somente da vontade política das administrações municipais por fazê-lo, mostrando-se como processos que envolvem a dinâmica da cidade como um todo, passando da disponibilidade de recursos para construção e manutenção, à disponibilidade de espaços físicos capazes de comportarem as estruturas nas localidades demandadas. Nesse bojo, aproximadamente $52 \%$ dos municípios analisados não construíram nenhum tipo de equipamento específico de esporte e lazer, seguindo uma distribuição relativamente uniforme, pois, ainda que se verifique a construção de novos equipamentos exclusivos para a prática do esporte institucionalizado, também se percebe a oferta de praças, ciclovias, e espaços para a prática de esportes radicais. Os dados coletados podem ser observados pela Tabela 2.

Em seus estudos, Soares e Guadanini (2018) identificaram que apenas um convênio, dos 21 que analisaram, construiu novas instalações para abrigar os núcleos do PELC. Nos demais, toda a verba foi utilizada para adequar os espaços já existentes. Outro dado compartilhado pelas autoras reforça a relevância dos equipamentos de esporte e lazer nas políticas públicas, uma vez que, em $60 \%$ dos casos, as parcerias realizadas pelo PELC com entidades locais são pautadas na cessão de espaços como quadras, salas e ginásios para a oferta de oficinas do Programa. Sob esse prisma, os aspectos ligados à manutenção desses espaços merecem destaque, por permitirem as condições adequadas de acesso e permanência da população.

É preciso considerar que parte do desafio está na operacionalização financeira do processo, que é perene 
Tabela 2. Equipamentos específicos de esporte e lazer construídos após a implementação do PELC nos municípios analisados.

\begin{tabular}{lcc}
\hline \multicolumn{1}{c}{ Tipo de Equipamento } & N & $\begin{array}{c}\text { Presença nos } \\
\text { municípios }\end{array}$ \\
\hline Não foram construídos novos & 10 & $52,6 \%$ \\
equipamentos & 8 & $42,1 \%$ \\
Academia ao Ar Livre & 3 & $15,8 \%$ \\
Campo de Futebol & 2 & $10,5 \%$ \\
Área para Esportes Radicais & 2 & $10,5 \%$ \\
Ciclovia & 2 & $10,5 \%$ \\
Praça & 1 & $5,3 \%$ \\
Quadra Poliesportiva & 1 & $5,3 \%$ \\
Outro & & \\
\hline
\end{tabular}

Fonte: elaborada pelos autores.

e se configura como despesa regular às gestões públicas. Os autores ressaltam que a gestão de infraestrutura de esporte e lazer deve considerar o aporte de recursos para a manutenção das instalações disponíveis, sobretudo em relação às ações de diagnóstico e prevenção de falhas em seu funcionamento. Além disso, reforçam o entendimento de que o uso de equipamentos em mau estado de conservação caracteriza risco permanente aos frequentadores, provocando, gradativamente, uma queda de sua capacidade de atendimento, além de exigir custos elevados para reforma ou recuperação.

Todavia, além de condições de manutenção no espaço físico propriamente dito, o acesso dos sujeitos também se condiciona à qualidade de outros serviços públicos, como a segurança e o transporte. Diante disso, avaliou-se os serviços de manutenção, permanência e acesso ligados aos equipamentos de esporte e lazer, sob a perspectiva das administrações municipais. No que tange aos serviços de manutenção, não foram encontradas uniformidades acerca do tema, sendo imperativo mencionar que, para além da destinação de equipes profissionais que atuem na limpeza dos espaços, por exemplo, a própria população deve se apropriar dos equipamentos, a ponto de zelar pela sua conservação. Esse é um processo educativo, que vai além das questões específicas do esporte e do lazer, cabendo também aos cidadãos a participação ativa na vida das cidades - o que pode ser estimulado por programas como o PELC.

Os itens relacionados aos serviços públicos auxiliares, que facilitam ou tornam possível o acesso das pessoas aos equipamentos de esporte e lazer, representados pelos descritores "segurança" e "transporte público", foram bem avaliados. Todavia, é preciso considerar que os respondentes fazem parte dos quadros municipais e, por esse motivo, pode existir conflito de interesses, sendo necessário confrontar a presente informação às percepções dos próprios frequentadores. No que diz respeito às estruturas que permitem a permanência das pessoas nos equipamentos, chamou atenção o resultado negativo obtido no descritor "fraldário". De fato, poucos equipamentos estão preparados para que as famílias com filhos pequenos possam experimentar os espaços públicos com qualidade.

As demais estruturas de permanência também foram avaliadas negativamente, a saber: estacionamento para carros e motos; estacionamento para bicicletas; postos de hidratação; e banheiros públicos. Com base nesses resultados, entende-se que as cidades ainda não cuidam adequadamente das condições de permanência das pessoas nos espaços públicos, revelando a necessidade de se debruçar no desenvolvimento de estratégias que permitam vivenciar as experiências de lazer e esporte neles potencializadas. Trata-se, portanto, de um ambiente urbano convidativo às relações sociais comunitárias, em que os sujeitos desfrutem de espaços e equipamentos confortáveis - sobretudo nas dimensões da segurança pública, transporte público, conforto visual e mobiliário.

O PELC, por se tratar de um programa institucionalizado desde 2003, tem apresentado evoluções significativas em relação às políticas de esporte e lazer. Todavia, não se pode negar que ainda existem caminhos a serem percorridos, para o enfrentamento e a resolução das mazelas que persistem em permear o cotidiano do Programa. Uma delas guarda relações com a extinção do Ministério do Esporte - ocorrida em 2019, fazendo com que a gestão do PELC se deslocasse para o Ministério da Cidadania, através da Secretaria Especial do Esporte, mantendo-se a Secretaria Nacional de Esporte, Educação, Lazer e Inclusão Social como referência. Compreende-se que tal movimento contribui para o declínio do prestígio institucional das ações destinadas ao lazer e ao esporte, reduzindo seu capital político e ampliando a disputa por recursos humanos, físicos e materiais.

\section{CONSIDERAÇÕES FINAIS}

Tematizando os equipamentos públicos destinados ao lazer e ao esporte em municípios que implementaram o PELC entre os anos de 2013 e 2017, o presente estudo identificou que ainda são maioria aqueles destinados às práticas hegemônicas, como os esportes coletivos e as ginásticas. Todavia, chama-se a atenção para os limites desta análise, haja visto que dos 105 municípios que compõem a amostra, 19 responderam ao questionário digital. Isso significa que os achados da pesquisa merecem estar sempre contextualizados às realidades das cidades em tela, evitando-se generalizações.

Isto posto, verificou-se o predomínio de instalações como ginásios e quadras poliesportivas, além de academias a céu aberto. Entretanto, alguns municípios demonstram algum deslocamento dessa lógica, ao investirem em espaços como praças, ciclovias e arenas de esportes radicais - o que pode estimular novos hábitos na população, ou até mesmo atender demandas até então reprimidas. Também foi possível verificar que as condições de acesso e permanência dos cidadãos merecem especial atenção por parte do poder público, 
uma vez que condiciona as vivências de lazer e esporte pela cidade.

Defende-se, portanto, a instituição de ações públicas intersetoriais, que orientem os atores políticos a conceberem democraticamente os espaços públicos, promovendo oportunidades de encontros e experiências diversificadas pelas cidades. Somado a isso, é indispensável considerar a adoção de medidas regidas pela justiça social, cujo objetivo está na superação das desigualdades sociais que limitam o acesso aos espaços físicos, à informação, à orientação e, por que não, à autonomia e à emancipação das pessoas. Somado a isso, é primordial conceber espaços e equipamentos considerando a manutenção de sua vida social, ou seja, o planejamento de ações que mobilizem a adesão e a aderência dos sujeitos que ali intencionam desenvolver suas práticas de lazer. Isso requer a valorização da participação cidadã e a destinação de recursos físicos, profissionais e financeiros, capazes de sustentar e gerenciar a manutenção do espaço.

\section{FINANCIAMENTO}

O presente estudo foi desenvolvido sem o apoio financeiro de qualquer agência de fomento.

\section{CONFLITOS DE INTERESSE}

Os autores declaram não haver conflitos de interesse.

\section{REFERÊNCIAS}

Abade NSN. As academias a céu aberto em Belo Horizonte: interfaces entre lazer e saúde [dissertação]. Belo Horizonte: Programa Pós-graduação Multidisciplinar em Estudos do Lazer, Faculdade de Educação Fìsica, Fisioterapia e Terapia Ocupacional, Universidade Federal de Minas Gerais; 2016.

Bramante AC, Pina WL. Gestão de espaços de esporte e lazer: material de apoio ao curso de ensino à distância. Belo Horizonte: CAED UFMG; 2018.

Brasil. Programa Esporte e Lazer da Cidade: diretrizes 2017. Brasília; 2017. 18 p.

Castro SBE. Políticas públicas para o esporte e lazer e o ciclo orçamentário brasileiro (2004-2011): prioridades e distribuição de recursos durante os processos de elaboração e execução orçamentária [tese]. Curitiba: Universidade Federal do Paraná; 2016.

Cotta TC. Metodologias de avaliação de programas e projetos sociais: análise de resultados e de impacto. Rev Serv Público. 1998;49(2):103-24.

Figuerôa KM, Sevegnani P, Mezzadri FM, Moraes e Silva M. Planejamento, ações e financiamento para o esporte em tempos de megaeventos. Motrivivência.
2014;26(42):55-71. http://dx.doi.org/10.5007/2175$8042.2014 \mathrm{v} 26 \mathrm{n} 42 \mathrm{p} 55$.

Gehl J. Cidades para pessoas. 2 ed. São Paulo: Perspectiva; 2013. 276 p.

Isayama HF, Dias C, Melo VA, Fortes R. O esporte como alternativa de lazer: análise de experiências brasileiras. In: Marinho A, Nascimento JV, Oliveira AABJ, editores. Legados do esporte brasileiro. Florianópolis: UDESC; 2014. p. 303-330.

Lopes TB, Isayama HF. Sobre o fazer técnico e o fazer político: a atuação do profissional de lazer no serviço público municipal. Rev Bras Cienc Mov. 2011;19(1):87-99.

Marchi W Jr, Almeida BS. O financiamento dos programas federais de esporte e lazer no Brasil (2004 a 2008). Movimento. 2010;16(4):73-92. http://dx.doi. org/10.22456/1982-8918.13103.

May T. Pesquisa social: questões, métodos e processos. Porto Alegre: Artmed; 2004.

Melo VA. "Projetos Sociais" de Esporte e lazer: reflexões, inquietações, sugestões. Quad Animac Educ Soc. 2008;1(7):1-24.

Melo VA, Fortes R. História do Esporte: panorama e perspectivas. Fronteiras. 2010;12(22):11-35.

Rechia S. Parques públicos de Curitiba: a relação cidadenatureza nas experiências de lazer [tese]. Campinas: Universidade Estadual de Campinas; 2003.

Silva LP, Pinto LMSM. Gestão participativa do PELC. Belo Horizonte: Editora UFMG; 2017. 97 p.

Soares MM, Guadanini AS. Resultados de monitoramento e avaliação dos programas Esporte e Lazer da Cidade (PELC) e Vida Saudável (VS). Licere. 2018;21(4):379-404. http:// dx.doi.org/10.35699/1981-3171.2018.1946.

Sodré ACA, Alves MFC. Relação entre emendas parlamentares e corrupção municipal no Brasil: estudo dos Relatórios do Programa de Fiscalização da Controladoria Geral da União. Rev Adm Contemp. 2010;14(3):414-33. http://dx.doi. org/10.1590/S1415-65552010000300003.

Starepravo FA. O esporte universitário paranaense e suas relações com o poder público [dissertação]. Curitiba: Universidade Federal do Paraná; 2006.

Ungheri BO, Isayama HF. Descentralização das políticas de esporte e lazer: estratégias adotadas por municípios no contexto do Programa Esporte e Lazer da Cidade (20132017). In: Isayama HF, Silva LP, editores. A Constituição Brasileira e as políticas públicas de esporte e lazer: produções em Programas de Pós-graduação. Campinas: Autores Associados; 2019. p. 217-242. (v. 1).

Ungheri B, Isayama H. Controle e participação social no Programa Esporte e Lazer da Cidade (PELC): reflexões sobre o papel e a atuação das instituições. Movimento. 2020;26:e26055. http://dx.doi.org/10.22456/19828918.100711. 